\title{
Tapping Pennisetum violaceum, a Wild Relative of Pearl Millet (Pennisetum glaucum), for Resistance to Blast (caused by Magnaporthe grisea) and Rust (caused by Puccinia substriata var. indica)
}

\author{
Rajan Sharma, ${ }^{\dagger}$ Shivali Sharma, and Vishal L. Gate \\ International Crops Research Institute for the Semi-Arid Tropics (ICRISAT), Patancheru Hyderabad 502324, Telangana, India
}

\begin{abstract}
Blast (Magnaporthe grisea) and rust (Puccinia substriata var. indica) are the two important foliar diseases of pearl millet (Pennisetum glaucum (L.) R. Br.) that can be best managed through host plant resistance. For identification of diverse sources of blast and rust resistance, 305 accessions of Pennisetum violaceum, a wild relative of pearl millet, were screened under greenhouse conditions against five pathotype-isolates of $M$. grisea and a local isolate of $P$. substriata var. indica collected from ICRISAT farm, Patancheru, India. Based on the mean blast score (1 to 9 scale), 17 accessions (IP 21525, 21531, 21536, 21540, 21594, 21610, 21640, 21706, 21711, 21716, 21719, 21720, 21721, 21724, 21987, 21988 , and 22160) were found resistant (score $\leq 3.0$ ) to all five patho-

individual rust-resistant ( $<5 \%$ severity) plants from 17 accessions were selected, grown in pots and advanced to next generation by selfing, and rescreened for three to four generations following pedigree selection to develop rust-resistant genetic stocks. Single plant selections from nine accessions (IP 21629, 21645, 21658, 21660, 21662, 21711, 21974, 21975 , and 22038 ) were found highly resistant to rust ( $0 \%$ rust severity) after four generations of pedigree selection and subsequent screening. Some of the blast-resistant accessions and rust-resistant genetic stocks are being utilized in a prebreeding program at ICRISAT for introgressing resistance genes from the wild into the parental lines of cultivated and potential pearl millet hybrids and varieties.
\end{abstract} types, and 24 accessions were resistant to four pathotypes of $M$. grisea. As there was variability for rust resistance within some accessions,
Keywords: germplasm, pathotype, prebreeding, resistance, wild relative
Pearl millet [Pennisetum glaucum (L.) R. Br.], a cross-pollinated diploid $(2 n=2 x=14) C_{4}$ species, is the sixth most important cereal crop predominantly grown for food and forage in the arid and semiarid tropical regions of the world (Shivhare and Lata 2017). It is cultivated on about 31.71 million ha with 28.36 million metric tons of production, with an average productivity of $894 \mathrm{~kg} \mathrm{ha}^{-1}$ in more than 30 countries across Asia, Africa, North and South America, Europe, and Oceania (FAOSTAT 2016). It is predominantly cultivated in Africa (63\% of global area and $48 \%$ of global production) and Asia (34\% of global area and $47 \%$ of global production). Pearl millet is primarily cultivated for grains, which are mainly used for making unleavened bread (chapatti) in south Asia, or as gruel, dumplings, couscous, and beer in Africa for human consumption, as well as for poultry feed and some industrial uses. It is also a valuable source of stover and green forage (Andrews and Kumar 1992).

Pearl millet is mainly cultivated under adverse agro-climatic conditions such as low or erratic rainfall, high temperature, and low soil fertility prevailing in millet-growing areas. Further, crop production and productivity is adversely affected by a number of abiotic stresses (drought and heat) and biotic stresses such as diseases (downy mildew [Sclerospora graminicola], blast [Pyricularia grisea; teleomorph: Magnaporthe grisea], rust [Puccinia substriata var. indica], ergot [Claviceps fusiformis], and smut [Moesziomyces penicillariae]). Breeding for downy mildew resistance has always been

${ }^{\dagger}$ Corresponding author: R. Sharma; r.sharma@cgiar.org

Funding: This work is part of the initiative "Adapting Agriculture to Climate Change: Collecting, Protecting and Preparing Crop Wild Relatives" which is supported by the Government of Norway. The project is managed by The Global Crop Diversity Trust (GS15005). For further information, visit the project website: http://www.cwrdiversity.org.

The author(s) declare no conflict of interest.

Accepted for publication 2 December 2019.

(C) 2020 The American Phytopathological Society the top priority in the pearl millet breeding programs in India owing to economic importance of the disease (Rai et al. 2014). However, during recent years, blast, also known as leaf spot, has gained equal importance due to its widespread occurrence in India. In fact, the disease has attained an alarming status requiring concerted efforts to breed for resistance to blast (Sharma et al. 2018). Rust, a foliar disease, reduces seed yield in hybrid seed production fields, and adversely affects biomass and quality of forage, and grain yields in pearl millet cultivars (Monson et al. 1986; Wilson et al. 1996). Natural occurrence of rust in severe form has been reported from the U.S.A., Brazil, and India (de Carvalho et al. 2006; Monson et al. 1986; Singh and King 1991). In India, rust is particularly more severe in hybrid seed production fields when the crop is grown in the postrainy season during January to April that coincides with cool nights $\left(15\right.$ to $\left.20^{\circ} \mathrm{C}\right)$ and warm days $\left(25\right.$ to $\left.34^{\circ} \mathrm{C}\right)$. During this period, dew formation on foliage in the morning hours helps urediniospores to germinate and cause infection.

Availability of diverse sources of resistance is a basic prerequisite for disease resistance breeding programs. Resistance sources are generally selected from the germplasm accessions of the cultivated crops that are conserved in the gene banks. However, interspecific as well as intergeneric crosses involving wild species have been successfully utilized for the transfer of disease resistance genes from wild relatives into well-adapted crop cultivars (Kaneko and Bang 2014). The ICRISAT gene bank at Patancheru, India, holds the largest collection of pearl millet germplasm (23,841 accessions from 53 countries), including 816 accessions of wild relatives (ICRISAT 2018). The genus Pennisetum (L.) Rich. is the largest in the tribe Paniceae and consists of over 140 species. On the basis of cross compatibility and the biological concept of species, Pennisetum germplasm has been classified into three gene pools; primary, secondary, and tertiary. The primary gene pool includes cultivated diploid pearl millet (Pennisetum glaucum) and its wild progenitor $(P$. violaceum $[=$ monodii Maire]) and weedy form (P. glaucum subsp. stenostachyum Kloyzesh ex. A. br. And Bouche). The secondary gene pool includes $P$. purpureum, an allotetraploid rhizomatous perennial, and the tertiary gene pool includes the remaining species that are cross-incompatible with cultivated pearl millet. Hanna and Wells (1989) discovered 
resistance to $M$. grisea in $P$. violaceum and found that resistance was controlled by three independent dominant genes. Resistance to rust has also been identified in $P$. violaceum from Senegal (Hanna et al. 1985). The present study was undertaken to screen 305 accessions of $P$. violaceum, which are maintained in the ICRISAT gene bank, against five pathotype-isolates of $M$. grisea and a field population of $P$. substriata var. indica for the identification of resistances sources to blast and rust diseases.

\section{Materials and Methods}

Seed source. Seed of 305 accessions of $P$. violaceum collected from 13 countries was obtained from the R. S. Paroda gene bank at ICRISAT, Patancheru, India.

Pathogen isolates. The monoconidial cultures of $M$. grisea pathotype-isolates Pg 45, Pg 53, Pg 56, Pg 118, and Pg 119 used in this study were obtained from the culture collection being maintained in our Cereals Pathology Lab, ICRISAT, Patancheru. The isolates were subcultured and maintained on oatmeal agar (OMA) medium at $25 \pm 1{ }^{\circ} \mathrm{C}$. The field population of $P$. substriata var. indica was collected from naturally infected pearl millet plants at ICRISAT farm, Patancheru.

Screening for blast resistance. Inocula of pathotype-isolates $\mathrm{Pg}$ 45, Pg 53, Pg 56, Pg 118, and Pg 119 were prepared as per the procedure described by Sharma et al. (2013). The 7-day-old cultures of $M$. grisea grown on OMA medium were used for inoculum multiplication. This was achieved by inoculating OMA medium with each isolate and incubating at $25 \pm 1{ }^{\circ} \mathrm{C}$ with $12 \mathrm{~h}$ darkness for 7 to 10 days. Spores were harvested by flooding the plates with sterile distilled water and scratching the fungal growth gently with a soft camel hair brush. The spore suspension was filtered through muslin cloth and adjusted to a desired concentration $\left(1 \times 10^{5}\right.$ spores $\left.\mathrm{ml}^{-1}\right)$ using a hemocytometer, and Tween 20 at $0.02 \% \mathrm{vol} / \mathrm{vol}$ was added to the suspension just before inoculation.

Seeds of 305 accessions and a blast susceptible check (ICMB 95444) were sown in $10-\mathrm{cm}$ diameter pots filled with sterilized soil/sand/farmyard manure mix $(2: 1: 1$ by volume) and placed in a greenhouse bay maintained at $30 \pm 2{ }^{\circ} \mathrm{C}$. The 12-day-old seedlings were spray-inoculated with an aqueous conidial suspension of each isolate separately, covered with polyethylene bags, and incubated at $25 \pm 1^{\circ} \mathrm{C}$ for $24 \mathrm{~h}$. After $24 \mathrm{~h}$ of incubation, bags were removed, and inoculated seedlings were transferred to greenhouse benches and exposed to $>90 \%$ RH under misting for 6 days. The blast screening experiments against each isolate $(\mathrm{Pg} \mathrm{45}, \mathrm{Pg} 53$, Pg 56, Pg 118, and Pg 119) were conducted in completely

Table 1. ANOVA for blast severity of 305 accessions of Pennisetum violaceum against five pathotype-isolates Pg 45, Pg 53, Pg 56, Pg 118, and Pg 119 of Magnaporthe grisea, and rust severity against field population of Puccinia substriata var. indica

\begin{tabular}{lccc}
\hline Source of variation & Degrees of freedom & Mean square & $\boldsymbol{F}$ probability \\
\hline Blast - Pg 45 & 304 & 4.9324 & $<0.001$ \\
Genotype & 301 & 0.5559 & \\
Residual & & & \\
Blast - Pg 53 & 304 & 2.5967 & $<0.001$ \\
Genotype & 292 & 0.4107 & \\
Residual & & & \\
Blast - Pg 56 & 304 & 2.9937 & $<0.001$ \\
Genotype & 301 & 0.4287 & \\
Residual & & & \\
Blast - Pg 118 & 304 & 2.4608 & $<0.001$ \\
Genotype & 300 & 0.5201 & \\
Residual & & & \\
Blast - Pg 119 & 304 & 3.4303 & $<0.001$ \\
Genotype & 288 & 0.5451 & \\
Residual & & & \\
Rust - Field population & 304 & 124.03 & $<0.001$ \\
Genotype & 302 & 74.7 & \\
Residual & & & \\
\hline
\end{tabular}

randomized design (CRD) with two replicates; 1 pot/replicate with 10 to 12 seedlings. Blast severity was recorded 8 days after inoculation using a 1 to 9 progressive rating scale (Sharma et al. 2013). Based on the disease score, accessions were categorized as resistant ( $\leq 3.0$ score), moderately resistant (3.1 to 5.0 score), and susceptible ( $>5.0$ score).

Screening for rust resistance. Urediniospores from the infected pearl millet foliage were collected using a vacuum spore collector and the spores were spread onto waxed paper to allow evaporation of excess moisture. The urediniospores were then transferred into glass vials and stored at $-80^{\circ} \mathrm{C}$. Prior to use, the glass vials containing urediniospores were placed in a water bath at $40^{\circ} \mathrm{C}$ for about $10 \mathrm{~min}$ to break spore dormancy. The spore suspension was prepared in sterilized distilled water and adjusted to a desired concentration $(\sim 1 \times$ $10^{5}$ spore $\mathrm{ml}^{-1}$ ) using a hemocytometer, and Tween 20 at $0.02 \%$ $\mathrm{vol} / \mathrm{vol}$ was added to the suspension just before inoculation to ensure uniform dispersal of spores (Thakur et al. 2011).

Seeds of 305 accessions and a rust susceptible check (ICMB $89111)$ were sown in $15-\mathrm{cm}$ diameter pots filled with sterilized soil/sand/farmyard manure mix $(2: 1: 1)$ and placed in a greenhouse bay maintained at $30 \pm 2{ }^{\circ} \mathrm{C}$. The pot-grown seedlings ( 15 days after sowing) were spray-inoculated with an aqueous urediniospores suspension $\left(\sim 1 \times 10^{5}\right.$ spore $\left.\mathrm{ml}^{-1}\right)$ of the local isolate of $P$. substriata var. indica. Inoculated seedlings were incubated in a moist chamber ( $>95 \% \mathrm{RH}, 25 \pm 1^{\circ} \mathrm{C}$ ) for about $18 \mathrm{~h}$ and then shifted to greenhouse benches at $25 \pm 2{ }^{\circ} \mathrm{C}$ under misting for 7 days. Seedlings were then transferred to a normal bay at $25 \pm 2{ }^{\circ} \mathrm{C}$ without misting. The experiment was conducted in CRD with two replicates; 1 pot/replicate with 12 to 15 seedlings. Rust severity (\%) was recorded 12 days after inoculation using a modified Cobb scale of 0 to $100 \%$ severity (Singh et al. 1997; Thakur et al. 2011). Plants were also observed for hypersensitive response (chlorotic specks without rust pustules) and the reaction was recorded. Rust severity was recorded on individual seedlings, and the mean severity of seedlings per pot was used for data analysis.

Selection for rust resistance. Within-accession variability for rust resistance was observed. Hence, resistant seedlings with $\leq 5 \%$ rust severity from 17 accessions were selected, selfed, and rescreened for three to four generations following selfing to develop rust-resistant genetic stocks during 2014-2016. Resistant plants from these accessions (three to five resistant plants from each accession) were selected and transplanted in $25-\mathrm{cm}$ pots. After transplanting, all the pots were placed in open space outside the greenhouse up to harvest. The heads were covered using the selfing bags upon emergence from the flag leaf to avoid chances of cross pollination. The selfed seeds harvested from the selected resistant plants were grown and $S_{1}$ plants (progenies of one resistant plant from each accession) were screened for rust resistance as described above. The procedure of single resistant plant selection and screening the next generation progenies and again selecting the resistant plants within an accession was continued up to $\mathrm{S}_{4}$ generation to stabilize resistance.

Data analysis. Analyses of variance (ANOVA) for blast scores against five pathotypes and rust severity was performed using the GENSTAT statistical package (version 10.1; Rothamsted Experiment Station, Herpenden, Herts, UK) to determine significant differences among $P$. violaceum accessions for disease resistance (Payne et al. 2009).

\section{Results}

Blast resistance. The susceptible check ICMB 95444 recorded $\geq 8.0$ score, indicating adequate disease pressure for effective and reliable screening for identification of blast resistance. ANOVA revealed highly significant $(P<0.001)$ differences among genotypes for blast reaction against five pathotype-isolates of $M$. grisea (Table 1). Numbers of resistant ( $\leq 3.0$ score), moderately resistant (3.1 to 5.0 score), and susceptible ( $>5.0$ score) accessions against five pathotypes are given in Figure 1. Based on mean blast score of two replications, 182 accessions were found resistant to pathotypeisolates $\mathrm{Pg} 53$, followed by 96 to $\mathrm{Pg} 56,89$ to $\mathrm{Pg} 119,86$ to $\mathrm{Pg} 45$, 
and 57 to Pg 118, whereas 180 accessions were moderately resistant to Pg 118. The highest number of susceptible accessions (103) was recorded against Pg 45. Multiple-pathotype resistance was also observed in the $P$. violaceum accessions. Seventeen accessions (IP 21525, 21531, 21536, 21540, 21594, 21610, 21640, 21706, 21711, 21716, 21719, 21720, 21721, 21724, 21987, 21988, and 22160) were found resistant to all the five pathotypes and 24 to any four pathotypes based on mean blast score of two replications (Table 2). Ninety-four accessions were susceptible to all five pathotypes, whereas 61 were resistant to any one pathotype, 60 to any two, and 49 to any three pathotypes. Most of the accessions having resistance to four or all five pathotypes originated from two countries, Chad and Niger, in west and central Africa (Table 2). Eight of the 17 accessions having resistance to all five pathotypes were collected from Chad and seven originated from Niger. Similarly, 12 of the 24 accessions having resistance to four pathotypes were from Niger and six from Chad.

Rust resistance. Significant variation for rust severity $(P<0.001)$ was also observed in the $P$. violaceum accessions (Table 1). Rust severity in the susceptible check ICMB 89111 was quite high (>70\%), indicating a reliable and effective disease screen. Based on mean rust severity of $305 P$. violaceum accessions, six (IP 21974, 21660, $21618,21975,21664$, and 21659) were considered resistant ( $\leq 10 \%$ rust severity), 52 moderately resistant (10.1 to $20 \%$ severity), while the remaining accessions were found susceptible ( $>20 \%$ rust severity).

Rust severity scores in $S_{0}$ to $S_{4}$ generations of the plants selected from 17 accessions are presented in Table 3 . The rust severity range in the accessions advanced by pedigree selections was 0 to $55 \%$ in $\mathrm{S}_{0}$ generation, which was reduced to 0 to $10 \%$ after four generations of selfing and rescreening. At each generation, individual resistant plants were selected, their progenies were screened in the next generation for rust resistance, and the pedigree of selected resistant plants from the specific accession was maintained. Selected plants from seven accessions, IP 21658, 21660, 21662, 21711, 21974, 21975, and 22038 were found rust free in $\mathrm{S}_{3}$ and $\mathrm{S}_{4}$ generations. Plants selected from IP 21629 and IP 21645 recorded 0 to 5\% rust severity in $S_{3}$ and further selections from these accessions were rust free ( $0 \%$ rust severity) in $\mathrm{S}_{4}$ generation.

\section{Discussion}

The screening of 305 accessions of $P$. violaceum led to the identification of 17 accessions resistant to all five $M$. grisea pathotypes used in this study, whereas 24 accessions were resistant to any four pathotypes. Pyramiding of several resistance genes in a single variety or identification of lines having resistance to different pathotypes of a pathogen has been advocated as a potential strategy to maintain disease resistance for a long period (Thakur et al. 2008; Van der Plank 1984). Crop wild relatives have helped modern agriculture by providing plant breeders with a broad pool of potentially useful genetic resources for crop improvement. For instance, the disease resistance genes in commercial tomato (Solanum lycopersicum) cultivars have been introgressed from wild genetic resources (Hajjar and Hodgkin 2007). Over 40 resistance genes have been derived from Solanum peruvianum and several other wild relatives (Rick and Chetelat 1995). Similarly, in wheat (Triticum aestivum), resistance genes to rusts (Puccinia triticina and Puccinia graminis f. sp. tritici), yellow dwarf virus, root lesion nematode (Pratylenchus spp.), powdery mildew (Blumeria graminis), wheat streak mosaic virus, and Hessian fly (Mayetiola destructor) have been introgressed from wild relatives such as Aegilops umbellulata, Haynaldia villosa, Secale cereale, Triticum timopheevii, and A. tauschii (Hajjar and Hodgkin 2007). In the case of pearl millet, resistance to blast in the U.S.A. has been derived from a weedy relative of pearl millet ( $P$. violaceum) obtained from Senegal (Hanna and Wells 1989). Therefore, the multiplepathotype resistant accessions identified from a wild relative of pearl millet in this study hold promise in breeding for blast resistance in pearl millet. More than $80 \%$ of $P$. violaceum accessions exhibiting resistance to four or all five $M$. grisea pathotypes in this study were collected from Chad and Niger. This indicates that $P$. violaceum accessions originating from the two neighboring countries, Chad and Niger, in west and central Africa possess genes conferring a high level of resistance to blast disease. Thus, the accessions from these countries could be used to introgress genes for blast resistance in the cultivated pearl millet.

Attempts were also made in the present study for the selection of rust resistance in $P$. violaceum accessions. Though none of the 305 accessions was completely resistant to rust, variability for rust resistance was observed within some accessions. As some plants within

\section{QResistant Moderately resistant m Susceptible}

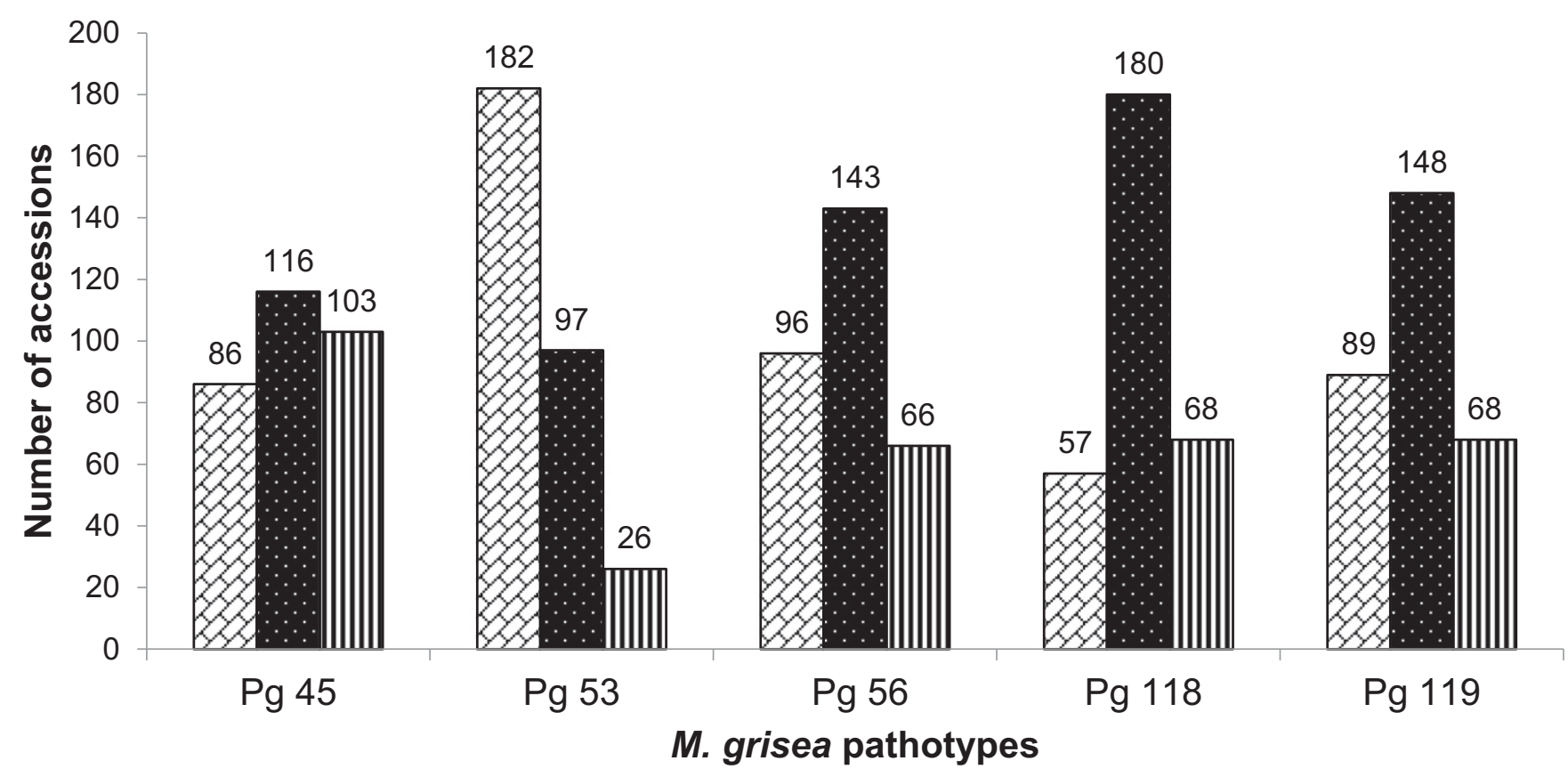

Fig. 1. Number of resistant, moderately resistant and susceptible accessions of Pennisetum violaceum against five pathotypes of Magnaporthe grisea. 
the accessions were found to have high rust resistance, attempts were made for the single-plant selection to stabilize resistance by selfing and rescreening the next generations for rust resistance. After 3 to 4 generations of selfing and screening, rust resistant selections have been identified from seven $P$. violaceum accessions (IP 21658, 21660, 21662, 21711, 21974, 21975, and 22038). The $P$. violaceum accessions, except IP 21630 and IP 22038, from which the selections for rust resistance were made also exhibited resistance to 1 to 5 pathotypes of $M$. grisea. This indicates that some of these accessions could be stabilized for resistance to both rust and blast disease, and eventually utilized in transferring rust and blast resistance in cultivated pearl millet. Hanna et al. (1985) employed two sources of major gene resistance derived from a wild subspecies ( $P$. violaceum) of pearl millet from Senegal in the breeding lines used to produce adapted cultivars for the southeastern U.S. Similarly, disease resistances in wild relatives of sunflower (Helianthus annuus) have been exploited and multiple sources of genetic resistance to different races of downy mildew (Plasmopara halstedii), as well as rust (Puccinia helianthi), have been transferred from wild $H$. annuus and $H$. praecox into new sunflower hybrids (Hajjar and Hodgkin 2007).
Resistance to rust has been reported in some pearl millet germplasm accessions and breeding lines (Singh et al. 1997; Wilson 1993). However, rust resistant lines such as ICMB 96222 and ICMR 06999, which were resistant to the Patancheru population of $P$. substriata var indica during 2008-09 (Sharma et al. 2009), were found susceptible to the pathogen isolate from the same location when included as resistant checks in the present study during 2014-16. This clearly indicates virulence change in the population of rust fungus at ICRISAT, Patancheru farm. Pathogenic variation in P. substriata var indica has been reported from the U.S.A. (Tapsoba and Wilson 1996; Wilson 1991). Therefore, rust resistant accessions identified in this study are potential sources to develop pearl millet cultivars resistant to the changed virulence of rust pathogens in India. Further, these accessions have been collected from different countries and the geographical diversity of these lines could represent diversity for the resistance genes as well (Caicedo 2008), which is desirable in breeding for resistance against different races of a pathogen.

Wild relatives, in general, have poor agronomic performance and are not directly used in breeding programs. Prebreeding is an approach of bringing the useful traits from the wild relatives into cultivated background for further use in breeding programs. The blast

Table 2. Promising accessions of Pennisetum violaceum having blast resistance against 4 to 5 pathotype-isolates (Pg 45, Pg 53, Pg 56, Pg 118, and Pg 119) of Magnaporthe grisea

\begin{tabular}{|c|c|c|c|c|c|c|c|c|}
\hline \multirow[b]{2}{*}{ IP No. } & \multirow[b]{2}{*}{ Origin } & \multicolumn{6}{|c|}{ Blast score (1-9 scale) $)^{a}$} & \multirow[b]{2}{*}{ Resistant to pathotypes (No.) } \\
\hline & & Pg 45 & Pg 53 & Pg 56 & Pg 118 & Pg 119 & Mean & \\
\hline 21525 & Niger & 2.4 & 2.2 & 2.6 & 2.6 & 2.8 & 2.5 & 5 \\
\hline 21531 & Sudan & 2.7 & 2.3 & 2.7 & 3.0 & 2.0 & 2.5 & 5 \\
\hline 21536 & Cameroon & 3.0 & 2.5 & 2.4 & 2.7 & 2.4 & 2.6 & 5 \\
\hline 21540 & Niger & 2.2 & 2.0 & 2.2 & 3.0 & 2.1 & 2.3 & 5 \\
\hline 21594 & Niger & 2.0 & 2.0 & 2.4 & 2.6 & 2.8 & 2.3 & 5 \\
\hline 21610 & Niger & 2.6 & 2.3 & 2.7 & 2.0 & 2.0 & 2.3 & 5 \\
\hline 21640 & Niger & 2.2 & 2.4 & 2.8 & 2.0 & 3.0 & 2.5 & 5 \\
\hline 21706 & Chad & 2.5 & 2.0 & 2.2 & 2.0 & 2.9 & 2.3 & 5 \\
\hline 21711 & Chad & 1.5 & 2.0 & 2.4 & 2.4 & 1.6 & 2.0 & 5 \\
\hline 21716 & Chad & 2.6 & 2.5 & 2.0 & 2.2 & 2.8 & 2.4 & 5 \\
\hline 21719 & Chad & 2.2 & 2.2 & 2.0 & 2.8 & 1.1 & 2.1 & 5 \\
\hline 21720 & Chad & 2.0 & 2.3 & 2.6 & 2.5 & 2.2 & 2.3 & 5 \\
\hline 21721 & Chad & 2.5 & 2.1 & 2.7 & 2.6 & 2.7 & 2.5 & 5 \\
\hline 21724 & Chad & 2.2 & 2.4 & 2.6 & 2.9 & 2.9 & 2.6 & 5 \\
\hline 21987 & Niger & 2.3 & 2.0 & 2.5 & 2.4 & 2.0 & 2.2 & 5 \\
\hline 21988 & Niger & 3.0 & 2.1 & 2.2 & 2.1 & 2.4 & 2.4 & 5 \\
\hline 22160 & Chad & 2.0 & 2.0 & 2.0 & 2.1 & 1.0 & 1.8 & 5 \\
\hline 21523 & Niger & 4.4 & 2.3 & 2.6 & 2.7 & 2.3 & 2.9 & 4 \\
\hline 21532 & USA & 3.6 & 2.1 & 2.8 & 2.8 & 2.0 & 2.7 & 4 \\
\hline 21538 & Niger & 3.0 & 5.4 & 2.8 & 2.8 & 2.6 & 3.3 & 4 \\
\hline 21544 & Niger & 2.8 & 2.1 & 2.8 & 4.6 & 2.2 & 2.9 & 4 \\
\hline 21557 & Niger & 2.8 & 2.2 & 2.5 & 3.1 & 3.0 & 2.7 & 4 \\
\hline 21564 & Niger & 3.0 & 2.3 & 2.7 & 4.8 & 2.5 & 3.1 & 4 \\
\hline 21657 & Mauritania & 2.0 & 3.2 & 3.0 & 2.9 & 2.7 & 2.7 & 4 \\
\hline 21664 & Senegal & 2.1 & 2.3 & 2.5 & 4.8 & 1.7 & 2.7 & 4 \\
\hline 21670 & Mali & 2.2 & 2.1 & 3.0 & 4.8 & 2.4 & 2.9 & 4 \\
\hline 21672 & Mali & 3.0 & 2.7 & 2.9 & 3.0 & 3.9 & 3.1 & 4 \\
\hline 21683 & Niger & 2.0 & 2.0 & 3.0 & 2.6 & 3.1 & 2.6 & 4 \\
\hline 21692 & Niger & 2.5 & 2.0 & 2.9 & 2.9 & 3.9 & 2.8 & 4 \\
\hline 21705 & Chad & 2.3 & 2.2 & 2.9 & 2.5 & 3.4 & 2.6 & 4 \\
\hline 21707 & Chad & 2.3 & 2.4 & 2.4 & 3.7 & 2.7 & 2.7 & 4 \\
\hline 21712 & Chad & 2.2 & 2.0 & 2.3 & 3.5 & 3.0 & 2.6 & 4 \\
\hline 21714 & Chad & 2.5 & 2.1 & 3.6 & 2.9 & 2.6 & 2.7 & 4 \\
\hline 21722 & Chad & 3.0 & 2.7 & 3.1 & 2.7 & 2.5 & 2.8 & 4 \\
\hline 21723 & Chad & 3.1 & 2.1 & 2.8 & 2.9 & 1.1 & 2.4 & 4 \\
\hline 21976 & Niger & 2.5 & 3.0 & 3.0 & 4.3 & 2.3 & 3.0 & 4 \\
\hline 21978 & Niger & 3.6 & 2.0 & 2.6 & 2.6 & 2.0 & 2.6 & 4 \\
\hline 21989 & Niger & 2.6 & 2.5 & 2.5 & 3.5 & 2.7 & 2.8 & 4 \\
\hline 21993 & Niger & 6.0 & 2.6 & 2.5 & 2.9 & 2.6 & 3.3 & 4 \\
\hline 22005 & Niger & 3.2 & 2.0 & 2.9 & 2.6 & 2.3 & 2.6 & 4 \\
\hline 22150 & Mauritania & 2.0 & 2.4 & 2.9 & 4.5 & 2.8 & 2.9 & 4 \\
\hline
\end{tabular}

${ }^{a}$ Mean of two replicates. 
Table 3. Rust severity of promising accessions of Pennisetum violaceum at succeeding stages of selections $\left(\mathrm{S}_{0}-\mathrm{S}_{4}\right)^{\mathrm{a}}$

\begin{tabular}{|c|c|c|c|c|c|c|c|c|c|c|c|c|}
\hline \multirow[b]{3}{*}{ IP number } & \multirow[b]{3}{*}{ Origin } & \multirow[b]{3}{*}{ Blast resistance $^{b}$} & \multicolumn{10}{|c|}{ Rust severity $(\%)^{c}$} \\
\hline & & & \multicolumn{2}{|c|}{$\mathrm{S}_{\mathbf{0}} \mathrm{c}$} & \multicolumn{2}{|c|}{$\mathbf{S}_{1}$} & \multicolumn{2}{|c|}{$\mathbf{S}_{\mathbf{2}}$} & \multicolumn{2}{|c|}{$\mathbf{S}_{\mathbf{3}}$} & \multicolumn{2}{|c|}{$\mathbf{S}_{4}$} \\
\hline & & & Mean & Range & Mean & Range & Mean & Range & Mean & Range & Mean & Range \\
\hline 21536 & Cameroon & 5 & 21.7 & $5-40$ & $n s^{d}$ & ns & 5.3 & $0-10$ & 0 & - & 0.8 & $0-10$ \\
\hline 21540 & Niger & 5 & 19.2 & $5-35$ & $\mathrm{~ns}$ & ns & 1.6 & $0-5$ & 0 & - & 0.9 & $0-10$ \\
\hline 21565 & Niger & 3 & 22.4 & $5-40$ & 3.0 & $0-3$ & 2.0 & $0-5$ & 0 & - & 2.2 & $0-10$ \\
\hline 21629 & Mali & 2 & 20.2 & $5-45$ & 8.7 & $3-20$ & 5.7 & $0-10$ & 0.6 & $0-2$ & 0 & - \\
\hline 21630 & Mali & 0 & 16.1 & $0-45$ & 29.3 & $3-45$ & 2.9 & $0-5$ & 0 & - & 0.8 & $0-10$ \\
\hline 21645 & Mauritania & 1 & 10.6 & $5-25$ & 8.7 & $3-20$ & 1.3 & $0-5$ & 3.5 & $0-5$ & 0 & - \\
\hline 21653 & Mauritania & 1 & 14.6 & $5-40$ & 1.0 & $0-3$ & 0.0 & - & 0 & - & 0.2 & $0-5$ \\
\hline 21658 & Senegal & 1 & 13.0 & $5-40$ & 15.6 & $3-40$ & 3.0 & $0-10$ & 0 & - & 0 & - \\
\hline 21659 & Senegal & 1 & 9.9 & $0-45$ & 3.0 & $0-3$ & 1.3 & $0-5$ & 0 & - & 0.4 & $0-5$ \\
\hline 21660 & Senegal & 3 & 6.1 & $0-25$ & 13.6 & $3-25$ & 1.3 & $0-5$ & 0 & - & 0 & - \\
\hline 21661 & Senegal & 3 & 13.1 & $0-35$ & 24.0 & $2-40$ & 9.0 & $0-15$ & 0 & - & 3.2 & $0-10$ \\
\hline 21662 & Senegal & 3 & 14.5 & $0-40$ & 12.2 & $3-40$ & 0.0 & - & 0 & - & 0 & - \\
\hline 21664 & Senegal & 4 & 9.8 & $0-40$ & 3.0 & $0-3$ & 2.0 & $0-5$ & 1.6 & $0-5$ & 0.5 & $0-5$ \\
\hline 21711 & Chad & 5 & 22.2 & $5-55$ & 10.8 & $3-20$ & 3.3 & $0-10$ & 0 & - & 0 & - \\
\hline 21974 & U.S.A. & 2 & 1.4 & $0-25$ & 0.0 & - & 0 & - & 0 & - & 0 & - \\
\hline 21975 & U.S.A. & 2 & 9.0 & $0-25$ & 7.8 & $0-30$ & 2 & $0-5$ & 0 & - & 0 & - \\
\hline 22038 & Mali & 0 & 15.6 & $0-35$ & $\mathrm{~ns}$ & $\mathrm{~ns}$ & 1.4 & $0-5$ & 0 & - & 0 & - \\
\hline
\end{tabular}

a $\mathrm{S}_{0}$ to $\mathrm{S}_{4}$ are selfing generations.

$\mathrm{b}$ Original accession resistant to number of Magnaporthe grisea pathotypes.

c Mean of two replicates.

d Not screened.

resistant accessions of $P$. violaceum were evaluated for regeneration ability and accessions IP 21544 and IP 21720 were selected as donors to generate prebreeding populations involving hybrid parents and forage cultivar as recipients. The introgression lines developed through the crossing of these $P$. violaceum accessions with the elite pearl millet lines are being screened against recently identified more virulent pathotypes of $M$. grisea. The resistant plants from these introgression lines are selected and transplanted in fields to obtain the selfed seed. The selfed seed from these selected plants will be screened for blast resistance against different pathotypes for 3 to 4 generations of selfing and screening to stabilize blast resistance introgressed from wild species in the cultivated pearl millet. Similarly, rust resistant genetic stocks of $P$. violaceum developed in this study will be used to develop prebreeding populations for further use in pearl millet breeding programs to develop rust resistant hybrid parental lines, and eventually commercial hybrids of pearl millet resistant to blast and rust diseases.

\section{Acknowledgments}

The authors are thankful to Head, Genebank, ICRISAT, Patancheru, India for providing the seed of 305 accessions of $P$. violaceum.

\section{Literature Cited}

Andrews, D. J., and Kumar, K. A. 1992. Pearl millet for food, feed, and forage. Adv. Agron. 48:89-139.

Caicedo, A. L. 2008. Geographic diversity cline of $R$ gene homologs in wild populations of Solanum pimpinellifolium (Solanaceae). Am. J. Bot. 95: 393-398.

de Carvalho, A. O., Soares, D. J., do Carmo, M. G. F., da Costa, A. C. T., and Pimentel, C. 2006. Description of the life-cycle of the pearl millet rust fungus-Puccinia substriata var. penicillariae with a proposal of reducing var. indica to a synonym. Mycopathologia 161:331-336.

FAOSTAT. 2016. http://www.fao.org/faostat/en/\#data/QC (accessed on 21 August 2018)

Hajjar, R., and Hodgkin, T. 2007. The use of wild relatives in crop improvement: A survey of developments over the last 20 years. Euphytica 156:1-13.

Hanna, W. W., and Wells, H. D. 1989. Inheritance of Pyricularia leaf spot resistance in pearl millet. J. Hered. 80:145-147.

Hanna, W. W., Wells, H. D., and Burton, G. W. 1985. Dominant gene for rust resistance in pearl millet. J. Hered. 76:134.

ICRISAT. 2018. http://genebank.icrisat.org/IND/Passport?Crop=Pearl+millet

Kaneko, Y., and Bang, S. W. 2014. Interspecific and intergeneric hybridization and chromosomal engineering of Brassicaceae crops. Breed. Sci. 64:14-22.
Monson, W. G., Hanna, W. W., and Gaines, T. P. 1986. Effects of rust on yield and quality of pearl millet forage. Crop Sci. 26:637-639.

Payne, R. W., Murray, D. A., Harding, S. A., Baird, D. B., and Soutar, D. M. 2009. GenStat for Windows, 14th Ed. VSN International, Hemel Hempstead.

Rai, K. N., Gupta, S. K., Sharma, R., Govindaraj, M., Rao, A. S., Shivade, H., and Bonamigo, L. A. 2014. Pearl millet breeding lines developed at ICRISAT: A reservoir of variability and useful source of non-target traits. SAT eJournal 1 : $1-13$

Rick, C., and Chetelat, R. 1995. Utilization of related wild species for tomato improvement, First International Symposium on Solanacea for Fresh Market. Acta Hortic. 412:21-38

Sharma, R., Gate, V. L., and Madhavan, S. 2018. Evaluation of fungicides for the management of pearl millet [Pennisetum glaucum (L.)] blast caused by Magnaporthe grisea. Crop Prot. 112:209-213.

Sharma, R., Thakur, R. P., Rai, K. N., Gupta, S. K., Rao, V. P., Rao, A. S., and Kumar, S. 2009. Identification of rust resistance in hybrid parents and advanced breeding lines of pearl millet. J. SAT Agric. Res. 7:1-4. http:// ejournal.icrisat.org/Volume7/Sorghum_Millets/PM704.pdf

Sharma, R., Upadhyaya, H. D., Manjunatha, S. V., Rai, K. N., Gupta, S. K., and Thakur, R. P. 2013. Pathogenic variation in the pearl millet blast pathogen, Magnaporthe grisea and identification of resistance to diverse pathotypes. Plant Dis. 97:189-195.

Shivhare, R., and Lata, C. 2017. Exploration of genetic and genomic resources for abiotic and biotic stress tolerance in pearl millet. Front. Plant Sci. 7:2069.

Singh, S. D., and King, S. B. 1991. Pearl millet rust - present status and future research needs. Int. J. Trop Plant Dis. 9:35-52.

Singh, S. D., Wilson, J. P., Navi, S. S., Talukdar, B. S., Hess, D. E., and Reddy, K. N. 1997. Screening techniques and sources of resistance to downy mildew and rust in pearl millet. Information Bulletin no. 48. ICRISAT, Patancheru, Andhra Pradesh, India.

Tapsoba, H., and Wilson, J. P. 1996. Pathogenic variation in Puccinia substriata var. indica in the southeastern United States and screening for resistance in pearl millet germplasm. Plant Dis. 80:395-397.

Thakur, R. P., Rai, K. N., Khairwal, I. S., and Mahala, R. S. 2008. Strategy for downy mildew resistance breeding in pearl millet in India. J. SAT Agric. Res. 6:1-11.

Thakur, R. P., Sharma, R., and Rao, V. P. 2011. Screening techniques for pearl millet diseases. Information Bulletin no. 89. ICRISAT, Patancheru, Andhra Pradesh, India.

Van der Plank, J. E. 1984. Disease Resistance in Plants. Academic Press, New York.

Wilson, J. P. 1991. Detection of pathogenic races of Puccinia substriata var. indica in the U.S. Phytopathology 81:815 (Abstract).

Wilson, J. P. 1993. Two new dominant genes for resistance to pearl millet rust. Phytopathology 83:1395 (Abstract).

Wilson, J. P., Hanna, W. W., and Gascho, G. J. 1996. Pearl millet grain yield loss from rust infection. J. Prod. Agric. 9:427-441. 